\title{
Reducing Crosspoints on Multistage Switching by Using Batcher Banyan Switches
}

\author{
M. Zulfin' ${ }^{1}$, Suherman' ${ }^{1}$, Maksum Pinem ${ }^{1}$, Rahmad Fauzi ${ }^{1}$, M. Razali ${ }^{2}$ \\ $\left\{\right.$ m.zulfin@usu.ac.id $\left.{ }^{1}\right\}$ \\ ${ }^{1}$ Electrical Engineering Department, Universitas Sumatera Utara, Indonesia \\ ${ }^{2}$ Institut Teknologi Medan, Indonesia
}

\begin{abstract}
Multistage switching is generally built by using crossbar switches in according to Clos architecture which has small blocking probabilities. However, number of cross points increases significantly to numbers of input output. This paper analyses the implementation of Batcher Banyan configuration to multistage switching system to reduce number of cross points. As Batcher Banyan sorts input to output ports, besides reducing cross points, it avoids collision among its input output. The Clos crossbar multistage switching requires up to $1,560,576$ cross points with $6.9 \times 10^{-17}$ blocking probability, but Batcher Banyan needs only 294,912 cross points, $429.17 \%$ lower, with zero blocking probability for the same numbers of input output.
\end{abstract}

Keywords: Clos Multistage switching, Crossbar switches, Batcher Banyan.

\section{Introduction}

Switch routes packets from sources to destinations. Switch is used whether for circuit switched network such as telephone exchange or packet switched network such as router (Sani A, 2018). As there are many sources or input ports and destinations or output ports, crossbar switches are employed.

The number of switches increases to number of input output. One way to reduce number of switches is by using certain switch arrangement such as multistage switching. Figure 1 shows the arrangement of switches using Clos architecture (Clos, 1953).

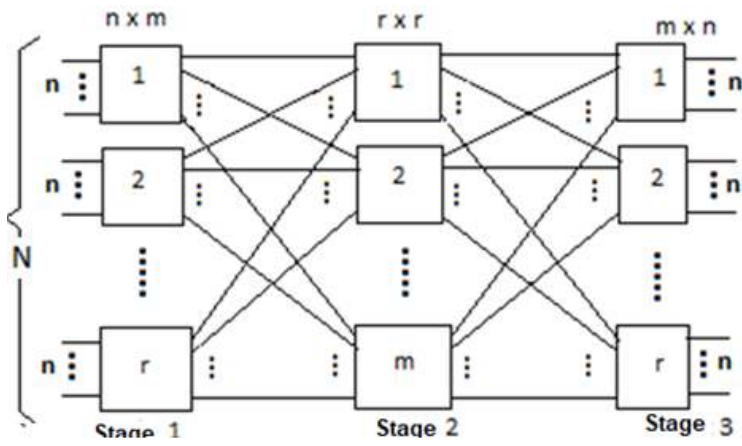

Fig. 1. Multi stage Switching.

The individual switches are arranged into $\mathrm{n} \times \mathrm{m}, \mathrm{r} \times \mathrm{r}$ and $\mathrm{m} \times \mathrm{n}$ switch modules. These modules are interconnected forming multistage switching. If $\mathrm{p}$ is the probability an input and an output links are busy, then the probability a certain link between switches is:

$\mathrm{p}^{\prime}=\mathrm{p} / \mathrm{m}$ 
The chance of a path between an input and an output is free is:

$q^{\prime}=\left(1-p^{\prime}\right)^{2}$

Since there is $\mathrm{m}$ possible links that can be used, the blocking probability is:

$\mathrm{Pb}=\left[1-\left(1-\mathrm{p}^{\prime}\right)^{2}\right]^{\mathrm{m}}$

If there are n-1 active links in the switching stage 1 input, then the probability of blocking is given by:

$$
P_{B}=\left[1-\left[1-(\mathrm{n}-1) \mathrm{p}^{\prime}\right]^{2}\right]^{m}
$$

Closs network is a three stage switching system where each stage consists of some crossbar switches. A symmetric Clos with triple parameters $(\mathrm{m}, \mathrm{n}, \mathrm{r})$ where $\mathrm{m}$ is the number of middle switch, $\mathrm{n}$ is number of input or output port in each switch, and $\mathrm{r}$ is number input and output switch. The middle switch of Clos network has one link connecting input switch and one link to every output switch.

For instance, Clos network of $(3,3,4)$ has $m=3, n=3, r=4$. At first stage it has 4 switching elements of $3 \times 3$, and at stage 2 has 3 switching elements of $4 \times 4$ and at third stage 4 switching elements of $3 \times 3$. Figure 2 shows the Clos $(3,3,4)$ network and Figure 3 the Clos $(5,3,4)$ (Danny, William J. and Towles, B. 2004).

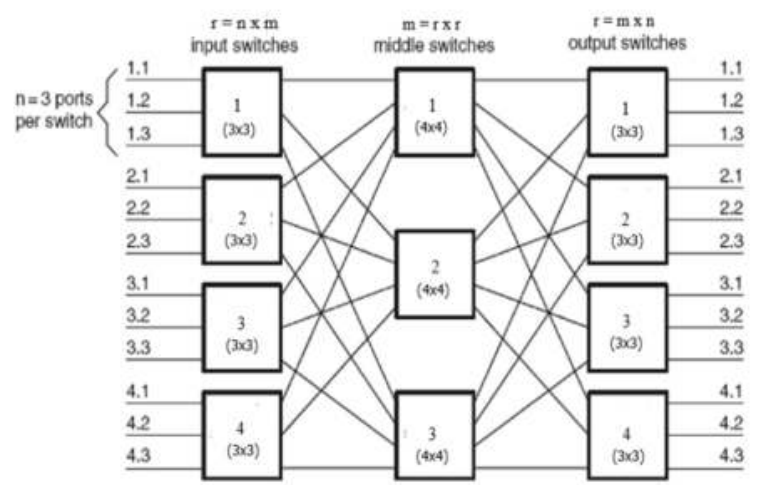

Fig. 2. Switching Clos $(3,3,4)$.

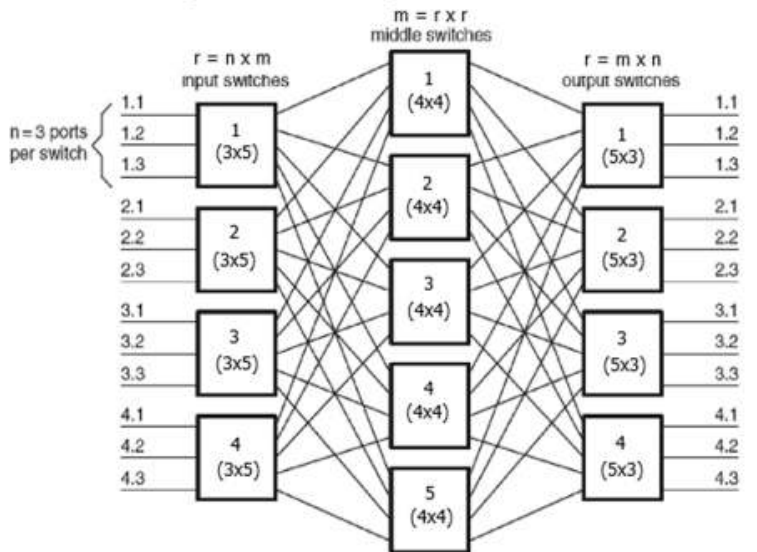

Fig. 3. Switching Clos $(5,3,4)$.

Blocking occurs when number of output ports is less than the input ports. Clos multistage switching experiences blocking approximated by the following equation (Lee, 1955):

$P_{B}=\frac{(u !)^{2}(2-p)^{2 u-m} p^{m}}{m !(2 u-m) !}$ 
Number of switches required (cross points, CP) to form $\mathrm{N} \mathrm{x} \mathrm{N}$ input output is (Clos, 1953): $\mathrm{CP}=2(\mathrm{~N} / \mathrm{n}) \mathrm{nk}+\mathrm{k}(\mathrm{N} / \mathrm{n})^{2}$

This blocking probability is sometimes accepted but some researchers use additional method, for instance, by adding buffer in front of or at the end of switching module (Garcia, 1990; M. Karol, 1987).

This paper analyses cross point and blocking probability reductions by using Batcher (Narashima, 1988) and Banyan switches to form multistage switching.

\section{Batcher And Banyan}

Batcher is a sorting circuit. It is developed by a $2 \times 2$ switch that works by using the following rules (Batcher, 1968):

- If there are two messages within its two-inputs, then the information with higher header value will be passed to the upper output port and the other to the lower one.

- If there is only one message in one of its input-ports, the message will be passed into the upper output port.

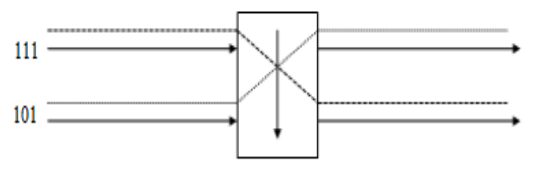

a. Two messages

101

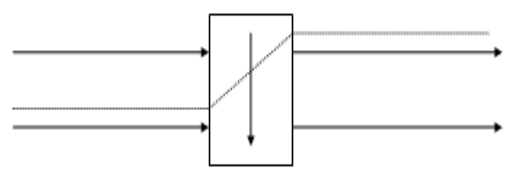

b. One message

fig. 4. Batcher Switch.

Batcher network with $\mathrm{N}=8$ is shown in Figure 5 (Hunter, 1997). Batcher switch $\mathrm{N}$ input and $\mathrm{N}$ output has $\log _{2} \mathrm{~N}\left(1+\log _{2} \mathrm{~N}\right) / 2$ stages and $\mathrm{N} \log _{2} \mathrm{~N}$ switching elements. As each element has $2 \times 2$ (4 crosspoints) then, the total $\mathrm{CP}$ is:

$\mathrm{CP}=4 \mathrm{~N} \log _{2} \mathrm{~N}$

(7)

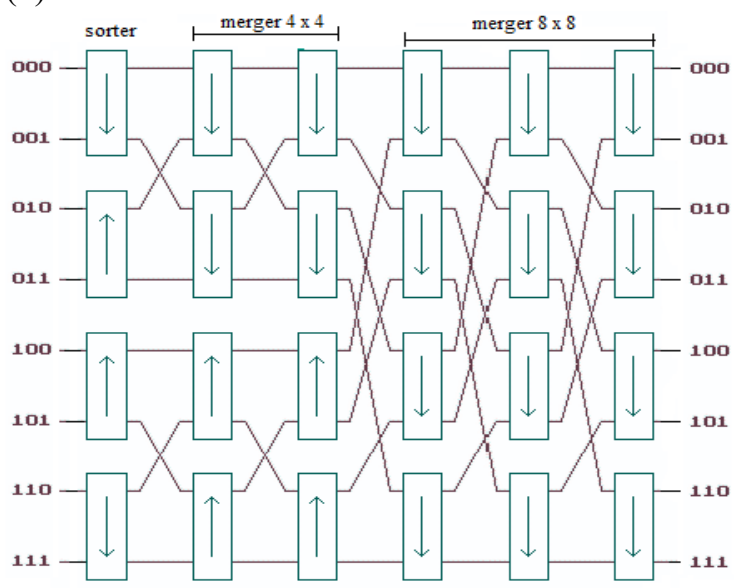

Fig. 5. Batcher Multistage Switching. 
Banyan topology is a self routing network; where messages enter this network find the destined output by using their message header. It does not require centralized control. Banyan network connects $\mathrm{N}$ inputs to $\mathrm{N}$ outputs requires $\log _{2} \mathrm{~N}$ stages and $\mathrm{N} / 2 \log _{2} \mathrm{~N}$ switching elements. So that the total CP required developing $\mathrm{NxN}$ switching system is (Goke L.R. dan Lipovski, 1973):

$\mathrm{CP}=2 \mathrm{~N} \log _{2} \mathrm{~N}$

However, Banyan has weakness as its blocking probability is still not zero. The probability blocking is even higher than Clos switch. Figure 6 illustrates the blocking in the first stage.

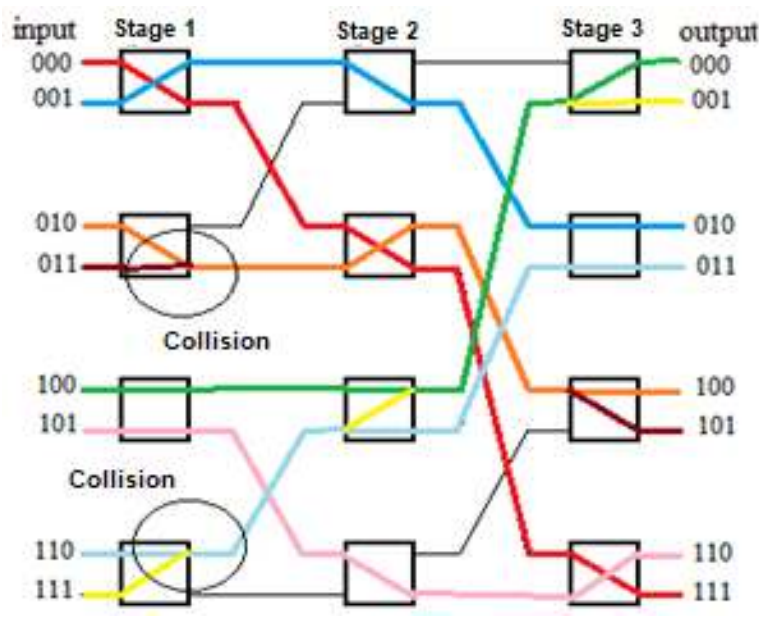

Fig. 6. Banyan Switching Blocking.

\section{Switch Combination}

In order to reduce cross point number in crossbar switch, Batcher and Banyan switches are combined. To avoid the blocking within Banyan network, Batcher switch is inserted in the first stage of Banyan multistage switching system. To interconnect both systems, link shuffle as shown in Figure 4 is employed (Patel, 1981).The link shuffle is to ensure that input messages are sorted before entering Banyan.

As a result, Batcher-Banyan multistage switching is obtained (Figure 7). Random inputs are sorted before entering Banyan. Packet goes to output 000 arriving at Banyan through shuffle 000. Packet goes to output 001 arriving at Banyan via shuffle 001. By doing this, all packets experience no conflict and no blocking occurred (Zulfin, 2015). 


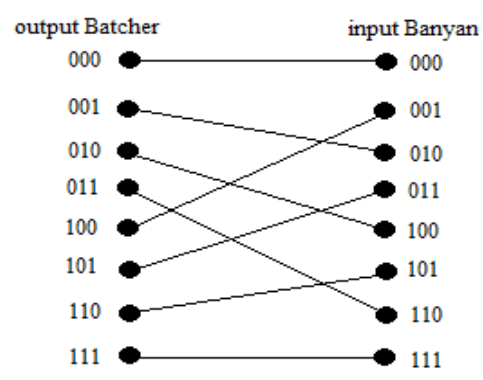

Fig. 7. Link Shuffle.

Figure 8 shows Batcher-Banyan size 8 × 8 (Hunter, 1997).

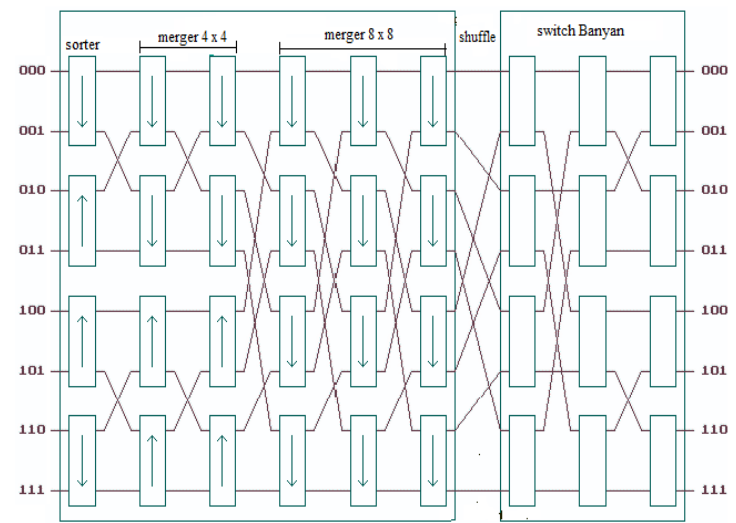

Fig. 8. Batcher-Banyan with link shuffle size $8 \times 8$.

Batcher-Banyan multistage switching with size of $\mathrm{NxN}$ requires total crosspoint of switch Batcher combined with switch Banyan, which is:

$\mathrm{CP}=4 \mathrm{~N} \log _{2} \mathrm{~N}+2 \mathrm{Nlog}_{2} \mathrm{~N}$

(9)

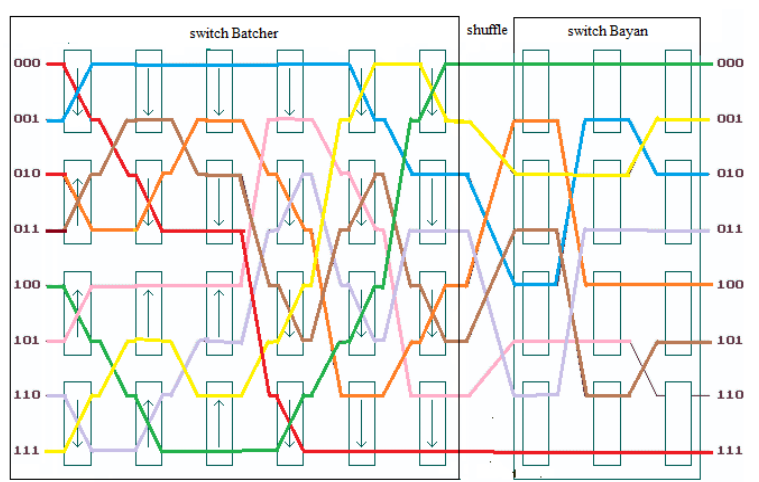

Fig. 9. Batcher-Banyan Multi stage Switching. 


\section{Switching Comparisons}

In order to compare the crossbar multistage switching and Batcher-Banyan multistage switching systems, number of cross points and probability of blocking are compared.

The number of stage is set to be 3, the input or output is set to be $16,64,256,1024$ and 4096. Table 1 shows the results.

Table 1. Cross point comparisons

\begin{tabular}{lll}
\hline \multirow{2}{*}{ Input-Output (N) } & \multicolumn{2}{l}{ Crosspoint } \\
\cline { 2 - 3 } & Crossbar & Batcher-Banyan \\
\hline 16 & 336 & 256 \\
\hline 64 & 2,880 & 2,176 \\
\hline 256 & 23,808 & 12,288 \\
\hline 1,024 & 193,536 & 61,440 \\
\hline 4,096 & $1,560,57$ & 294,912 \\
& 6 & \\
\hline
\end{tabular}

The Batcher-Banyan cross points are much lower than the crossbar multistage switching system. For $\mathrm{N}=16$, the number of cross point of Batcher-Banyan is $31.25 \%$ lower than crossbar. For $\mathrm{N}=4,096$, the difference rocketed to $429.17 \%$.

These differences increase following the Equation 6, where y is the difference percentage and $\mathrm{x}$ is the number of input or output.

$\mathrm{y}=0.0561 \mathrm{x}^{0.5146}$

This equation is obtained from the regression analysis of Figure 9.

Table 2. Blocking probability comparisons.

\begin{tabular}{|c|c|c|}
\hline \multirow[t]{2}{*}{ Input-Output (N) } & \multicolumn{2}{|c|}{ Blocking probability } \\
\hline & Crossbar & Batcher-Banyan \\
\hline 16 & $0^{-2}{ }^{6.3 \times 1}$ & 0 \\
\hline 64 & $0^{-3}{ }^{6.6 \times 1}$ & 0 \\
\hline 256 & $0^{-5}{ }^{6.8 \times 1}$ & 0 \\
\hline 1.024 & $0^{-9}{ }^{6.8 \times 1}$ & 0 \\
\hline 4.096 & $0^{-17}{ }^{6.9 \times 1}$ & 0 \\
\hline
\end{tabular}

Further, Batcher-Banyan maintains the multistage switching system working without blocking. While the crossbar exerts probability of blocking from $6.3 \times 10^{-2}$ for $\mathrm{N}=16$ to $6.9 \times 10^{-}$ 17 for $\mathrm{N}=4096$ (Table 2). 


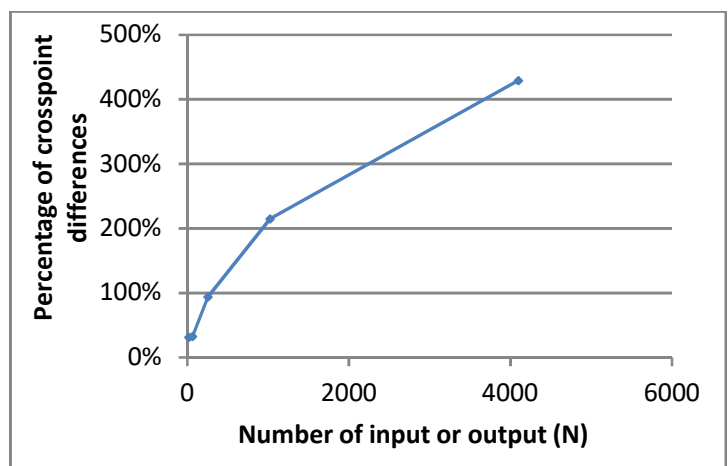

Fig. 10. Batcher-Banyan Multi stage Switching.

\section{Conclusion}

The Batcher-Banyan multistage switching system has many advantages over the crossbar multistage switching system. Beside Batcher-Banyan switch is a self-routing switching system that does not require complex control, Batcher-Banyan Multistage switching system has lower number of cross point compared to crossbar switch. In addition, Batcher-Banyan is purely non-blocking. Future wok may consider digital switch presence in comparing both systems.

\section{References}

[1] Batcher, K. E. (1968). Sorting Networks and Their Applications. Spring Joint Computer Conference, Goodyear Aerospace Corporation, Akron, Ohio, 32, 307-314.

[2] Clos, C. (1953). A Study of Non-Blocking Switching Networks. The Bell System Technical Journal.

[3] Garcia, H. S. K. and A. L. (1990). A Self-Routing Multistage Switching Network for Broadband ISDN. IEEE Journal on Selected Area in Communication, 8(3).

[4] Goke L.R. dan Lipovski, G. J. (1973). Banyan Networks for Partitioning Multiprocessing Systems. In Proceeding 1st Annual Computer Architecture Conference (pp. 21-28).

[5] Hunter, D. K. (1997). Encyclopedia of Information Technology. In Encyclopedia of Information Technology (p. Vol. 42 No.27). Marcel Dekker, New York.

[6] Lee, C. Y. (1955). Analysis of Switching Networks. Bell System Technical Journal.

[7] M. Karol, M. H. dan S. M. (1987). Input Versus Output Queueing on A Space-Division Packet Switch. IEEE Transaction Communication, COM(35), 1347-1356.

[8] Narashima, M. J. (1988). The Batcher-Banyan Self-Routing Network: Universality and Simplification. IEEE Transaction on Communication, 36(10).

[9] Patel, J. H. (1981). Performance of Processor-Memory Interconnections for Multiprocessors. IEEE Transactions on Computers, 30(10).

[10] Sani A. (2018). Multistage switching hardware and software implementations for student experiment purpose. IOP Conference Series: Materials Science and Engineering, 309(1), 12097.

[11] Zulfin, M. (2015). Perbaikan Internal Blocking Jaringan Switching Banyan dengan Penyortir Batcher. Jurnal Ilmiah Teknologi Harapan, 5(2). 